\title{
ARTICLE
}

Received 20 Nov 2015 | Accepted 31 Mar 2016 | Published 3 May 2016

DOl: $10.1038 /$ ncomms11486

OPEN

\section{The Arabidopsis NPF3 protein is a GA transporter}

Iris Tal ${ }^{1, \star}$, Yi Zhang ${ }^{2, \star}$, Morten Egevang Jørgensen ${ }^{3, \star}$, Odelia Pisanty ${ }^{1}$, Inês C.R. Barbosa ${ }^{4}$, Melina Zourelidou ${ }^{4}$, Thomas Regnault ${ }^{4}$, Christoph Crocoll ${ }^{3}$, Carl Erik Olsen ${ }^{5}$, Roy Weinstain ${ }^{1}$, Claus Schwechheimer ${ }^{4}$, Barbara Ann Halkier ${ }^{3}$, Hussam Hassan Nour-Eldin ${ }^{3}$, Mark Estelle ${ }^{2}$ \& Eilon Shani ${ }^{1}$

Gibberellins (GAs) are plant hormones that promote a wide range of developmental processes. While GA signalling is well understood, little is known about how GA is transported or how GA distribution is regulated. Here we utilize fluorescently labelled GAs (GA-FI) to screen for Arabidopsis mutants deficient in GA transport. We show that the NPF3 transporter efficiently transports GA across cell membranes in vitro and GA-Fl in vivo. NPF3 is expressed in root endodermis and repressed by GA. NPF3 is targeted to the plasma membrane and subject to rapid BFA-dependent recycling. We show that abscisic acid (ABA), an antagonist of GA, is also transported by NPF3 in vitro. ABA promotes NPF3 expression and GA-Fl uptake in plants. On the basis of these results, we propose that GA distribution and activity in Arabidopsis is partly regulated by NPF3 acting as an influx carrier and that GA-ABA interaction may occur at the level of transport.

\footnotetext{
${ }^{1}$ Department of Molecular Biology and Ecology of Plants, Tel Aviv University, Tel Aviv 69978, Israel. ${ }^{2}$ Howard Hughes Medical Institute and Section of Cell and Developmental Biology, University of California San Diego, La Jolla, California 92093, USA. ${ }^{3}$ DynaMo Center, Faculty of Science, University of Copenhagen, Thorvaldsensvej 40, 1871 Frederiksberg C, Denmark. ${ }^{4}$ Plant Systems Biology, Technische Universität München, 85354 Freising, Germany. ${ }^{5}$ Department of Plant and Environmental Sciences, Faculty of Science, University of Copenhagen, Thorvaldsensvej 40, 1871 Frederiksberg C, Denmark. ${ }^{\star}$ These authors contributed equally to this work. Correspondence and requests for materials should be addressed to M.E. (email: mestelle@ucsd.edu) or to E.S. (email: eilonsh@post.tau.ac.il)
} 
nlike animals, plants are sessile organisms that must integrate biotic and abiotic stimuli with their genetic programme to grow and reproduce in a dynamic environment. Growth and development are regulated in response to environmental inputs such as temperature, nutrient status, water, pathogens and light. To enable signal integration, plants employ hormone systems that are exquisitely controlled at multiple levels such as hormone biosynthesis, metabolism, perception and signalling ${ }^{1-3}$. In addition, the distribution and cellular concentration of plant hormones are regulated, thereby enabling highly coordinated cellular responses ${ }^{4-9}$. For example, the combined activities of auxin influx and efflux carrier proteins generate local hormone maxima, minima and auxin gradients that are required for various developmental processes $^{10,11}$. The recent identification of abscisic acid (ABA), strigolactone and cytokinin transporters ${ }^{6-9,12}$ implies that, like auxin, the in planta distribution of these and possibly also other hormones is determined by transporters.

Gibberellins (GAs) are tetracyclic diterpenoid hormones that control many developmental processes such as seed germination, root and shoot elongation, flowering and fruit patterning. The genetic or agrochemical manipulation of GA biosynthesis or signalling is a widespread practice in agriculture. The best-known examples are the dwarfing alleles of wheat REDUCED HEIGHT1 and rice SEMIDWARF1 that are one of the foundations of the so-called 'Green Revolution' and resulted in enormous increases in global crop yields after World War $\mathrm{II}^{13}$. Whereas research over the past 15 years has elucidated the GA biosynthetic and signalling pathways at the molecular level, it remains to be determined precisely where GAs are active within the plant and how GAs are transported from sites of synthesis to sites of action. Studies using radiolabelled GA and grafting experiments with GA mutants, have demonstrated that GAs are mobile hormones and that their movement is essential for proper plant growth ${ }^{14-19}$. A recent Arabidopsis grafting experiment with a variety of GA biosynthetic mutants demonstrated long-distance transport of the inactive $\mathrm{GA}_{12}$ (ref. 20). Many GAs are membrane permeable weak acids that can accumulate in the cytoplasm due to an ion-trapping mechanism ${ }^{21}$. To explain how GAs can pass through the plasma membrane as a part of cell-to-cell transport, the existence of active GA carriers has been proposed ${ }^{22}$.

We have recently explored the in planta distribution of several bioactive GAs in Arabidopsis thaliana roots using custom-made fluorescein-tagged (fluorescent) GA molecules (GA-Fls) ${ }^{23}$. Interestingly, these biologically active GA-Fls specifically accumulated in the endodermal cells of the root elongation zone but not in the meristematic or differentiation zones, whereas free fluorescein was detected in all tissues ${ }^{23}$. The data suggest that the specific accumulation of GA-Fl in the endodermis is tightly regulated $^{23,24}$. However, the identity of GA transporters involved in this process has remained elusive.

Here we describe a search for GA transporters by screening for mutants defective in GA-Fl accumulation. We show that mutants lacking NPF3, a poorly characterized member of the NPF family, are deficient in the uptake of fluorescent GA into elongating root endodermal cells. NPF3 overexpression causes a striking accumulation of GA-Fl in all root cells and dramatic inhibition of root and shoot growth. Experiments in Xenopus oocytes show that NPF3 is an active GA importer. We also demonstrate that NPF3 transports $\mathrm{ABA}$ in oocytes, suggesting that $\mathrm{ABA}$ and GA transport may be linked through the dual specificity of several NPF transporters.

\section{Results}

NPF3 transports GA-Fl into elongating root endodermal cells. To identify putative GA transporters, we screened a collection of $\approx 180$ transfer DNA (T-DNA) insertion mutants of the ATP-binding cassette and the NITRATE TRANSPORTER1/ PEPTIDE TRANSPORTER (NPF) transporter family members for seedlings that were defective in GA-Fl accumulation in the root endodermis ${ }^{25,26}$ (Supplementary Data 1). Members of both transporter families have been shown to function as plant hormone transporters $6,8,9,12,27-30$. The screen was performed visually by testing 10 seedlings per T-DNA line using the confocal microscope. The screen identified a T-DNA line that was deficient in the accumulation of GA-Fl. The T-DNA insertion disrupted NPF3 (At1g68570, NPF3.1), a poorly characterized member of the NPF gene family (Fig. 1a) ${ }^{31,32}$. Two independent insertion mutants, $n p f 3-1$ (SALK_130095) and $n p f 3-2$ (GK-356G08) (Fig. 1b), accumulated very low levels of $\mathrm{GA}_{3}-\mathrm{Fl}$ and $\mathrm{GA}_{4}-\mathrm{Fl}$ in the elongating endodermal cells compared with the wild-type (WT) but accumulated normal levels of free Fl (Fig. 1c, Supplementary Fig. 1a). Reverse transcription-PCR (RT-PCR) experiments indicated that some regions of the NPF3 transcript accumulated to high levels in the T-DNA lines (Supplementary Fig. 1b,d-e); however, neither allele generated full-length NPF3 RNA (Supplementary Fig. 1b-c). Both T-DNA lines were backcrossed to Col-0. Genetic analysis revealed that the uptake defect segregated as a single recessive mutation completely linked to the insert $(n=100)$. These results suggest that NPF3 may be involved in GA transport into the elongating endodermal cells of the root.

NPF3 belongs to an evolutionarily conserved but strongly expanded and diversified family of transporters with 53 members in Arabidopsis. Arabidopsis NPF1.1 and NPF4.6/AIT1 transport auxin and ABA, respectively ${ }^{12,30}$. Recent work showed that various NPF proteins can transport GA, ABA and jasmonic acid-isoleucine (JA-Ile) ${ }^{33,34}$. NPF3 is conserved in all plant lineages and its orthologs share a high degree of identity ${ }^{26}$, suggesting a fundamental physiological role. Since loss of NPF3 function abolished $\mathrm{GA}_{3}-\mathrm{Fl}$ accumulation in the elongating endodermal cells we hypothesized that misexpressing $N P F 3$ in additional cell types would affect $\mathrm{GA}_{3}-\mathrm{Fl}$ accumulation in the root. We introduced a construct into Col- 0 plants in which NPF3 was fused to yellow fluorescent protein (YFP) and placed under the control of the $35 S$ promoter ( $p 35 S: N P F 3-Y F P$ ). NPF3 RNA levels were 16- and 5-fold higher (depending on the line) in $p 35 S: N P F 3-Y F P$ plants compared with WT plants (Supplementary Fig. 1d). Indeed, accumulation of $\mathrm{GA}_{3}-\mathrm{Fl}$ was markedly enhanced in these lines (Fig. 1c). This result strongly supports the hypothesis that NPF3 facilitates GA transport in planta. Overexpression of the NPF3 gene in reverse orientation ( $p 35 S$ :NPF3-antisense) resulted in two and threefold reduction (depending on the line) in NPF3 transcript levels compared with WT (Supplementary Fig. 1d) and in reduced $\mathrm{GA}_{3}-\mathrm{Fl}$ accumulation in elongating endodermis (Fig. 1c). Overall, the results indicate that $N P F 3$ is required for accumulation of $\mathrm{GA}_{3}-\mathrm{Fl}$ in endodermal cells in the root elongation zone.

NPF3 localization and regulation. Our results suggest that NPF3 is a GA transporter. Indeed, in silico analysis predicts a putative 12 transmembrane domain carrier protein (Supplementary Fig. 2a). Plant hormone transporters localize to the plasma

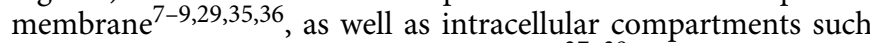
as the endoplasmic reticulum and vacuole ${ }^{37-39}$. To address NPF3 subcellular localization, we utilized our p35S:NPF3-YFP lines. Confocal microscopy of $p 35 S: N P F 3-Y F P$ root tips showed that NPF3 localizes to the plasma membrane and intracellular membrane compartments (Fig. 2a). By imaging NPF3-YFP in root tip cells where the vacuoles are small and by using chemical and genetic markers that stain the tonoplast and plasma 
a

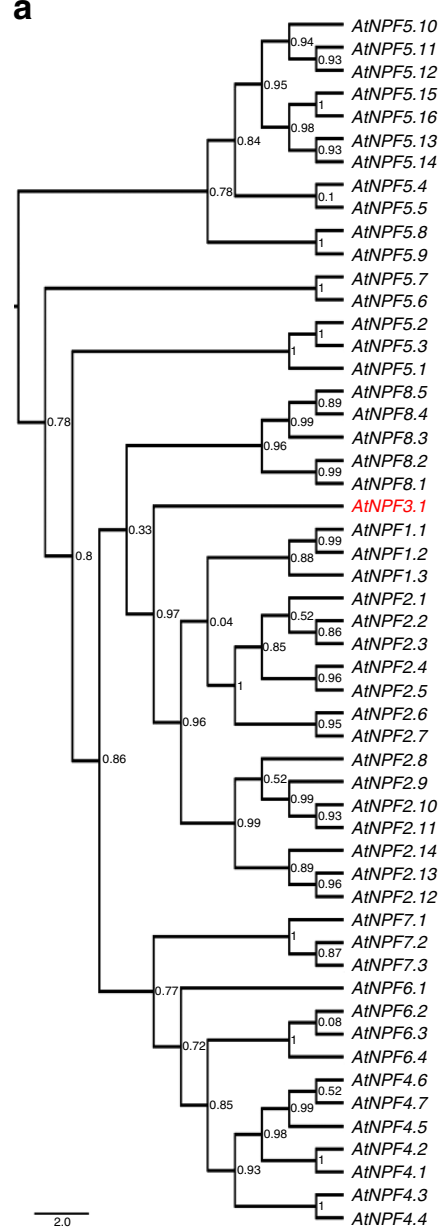

b

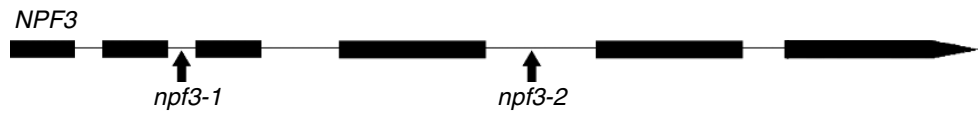

C

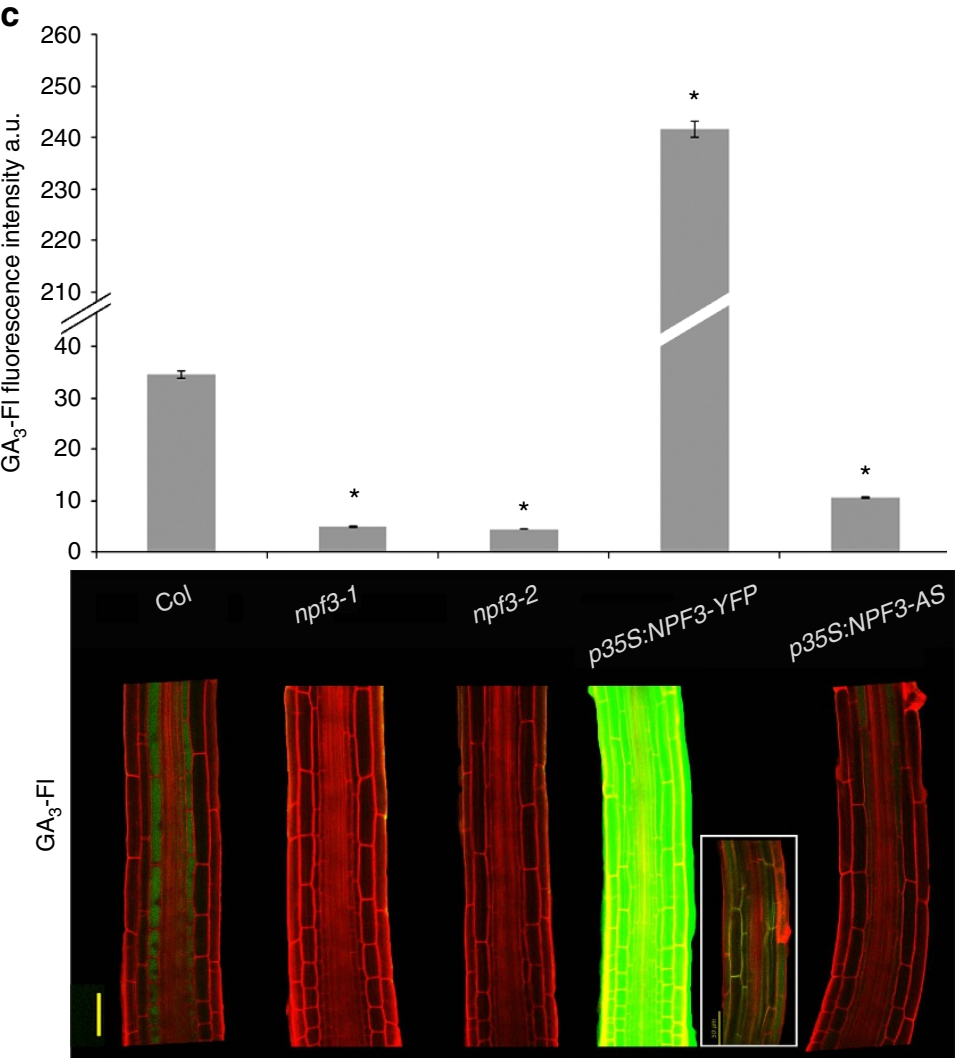

Figure 1 | NPF3 is required for GA-FI accumulation in the elongating endodermal cells of the root. (a) Phylogenetic tree of the Arabidopsis NPF (NRT/PTR) family. NPF3.1 (NPF3, At1g68570) shown in red. (b) NPF3 (At1g68570) gene model. Arrows indicate the positions of the T-DNA insertion for npf3-1 (SALK_130095) and npf3-2 (GK-356G08). (c) Quantification and distribution of fluorescently tagged GA $\mathrm{A}_{3}\left(\mathrm{GA}_{3}-\mathrm{FI}\right)$ in elongating endodermal cells of roots $(5 \mu \mathrm{M} \mathrm{GA} 3-\mathrm{Fl}, 3 \mathrm{~h}$ treatment). Top; quantification of fluorescence intensity averages \pm s.e. (4 roots imaged per genotype, 17 sampling points per root; $n=68$ ). ${ }^{*}$ Significantly different relative to Col at $P \leq 0.001$ by Student's $t$-test. Bottom, confocal images of representative roots. Box shows untreated p35S:NPF3-YFP root using the same imaging setup. AS, antisense. Bar, $50 \mu \mathrm{m}$.

membrane, we were able to rule out vacuolar localization (Fig. 2b and Supplementary Fig. 2b). These results seemingly contradict previous experiments involving transient expression in tobacco that suggested localization of NPF3 orthologs from cucumber (CsNitr1-L, CsNPF3.2) to chloroplasts ${ }^{32}$. Moreover, in silico analysis showed that the $\mathrm{N}$ terminus of Arabidopsis NPF3 lacks a chloroplast targeting sequence that is predicted for CsNitr1-L $L^{31}$. To further investigate NPF3 trafficking to the plasma membrane, we treated p35S:NPF3-YFP seedlings with Brefeldin A (BFA), an inhibitor of ARF-GTP exchange factors, for $15 \mathrm{~min}$ and imaged NPF3-YFP by confocal microscopy. This treatment resulted in the depletion of NPF3YFP from the plasma membrane and accumulation of the transporter in intracellular vesicles, indicating that NPF3 is rapidly targeted to the plasma membrane in a BFA-dependent manner (Fig. 2c). Consistent with this, we observed that BFAtreated roots are deficient in $\mathrm{GA}_{3}$-Fl uptake (Fig. 2d). Thus, NPF3 localization on the plasma membrane is required for $\mathrm{GA}_{3}-\mathrm{Fl}$ accumulation in the elongating endodermal cells. Co-treatments of $p 35 S: N P F 3-Y F P$ seedlings with GA or paclobutrazol (paclo; an inhibitor of GA synthesis) with and without BFA did not show a significant difference compared with respective control treatments, implying that NPF3 subcellular localization or its
BFA sensitivity are not directly affected by $\mathrm{GA}_{4}$ levels (Supplementary Fig. 2c-d).

According to published root cell-specific transcriptomic data ${ }^{40}$ and other publicly available microarray data, NPF3 is expressed in roots, albeit at very low levels. Interestingly, a high-resolution root spatiotemporal microarray expression map shows NPF3 transcripts at higher levels in the root endodermis compared with other tissues in roots (Fig. 2e) ${ }^{40}$. Moreover, additional support for endodermis localization of NPF3 was obtained by analysing cell type-specific expression data (Supplementary Fig. 3a) derived from microarray studies of RNA bound to ribosomes, which were immunoprecipitated by the use of epitope-tagged ribosomal protein from seedlings ${ }^{41}$. In combination, the localization of NPF3 transcripts and translation are consistent with a role for $\mathrm{NPF} 3$ in GA-Fl accumulation in the root endodermis.

Several plant hormone transporters are regulated at the transcriptional level by their hormone substrate $8,37,42$. To evaluate the response of NPF3 to GA, we analysed NPF3 transcript abundance following GA treatment. Ten-day-old Col-0 seedlings pretreated with paclo show strongly reduced NPF3 RNA levels in response to $10 \mu \mathrm{M} \mathrm{GA}_{4}$ treatment as measured by quantitative PCR experiments (Fig. 2f). In agreement, pNPF3:LUC (luciferase) 10-day-old seedlings treated 


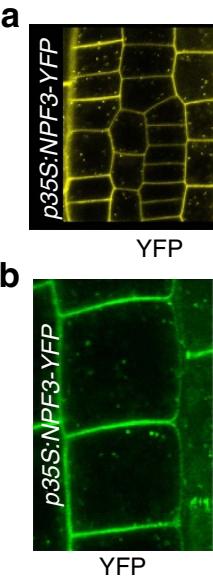

C
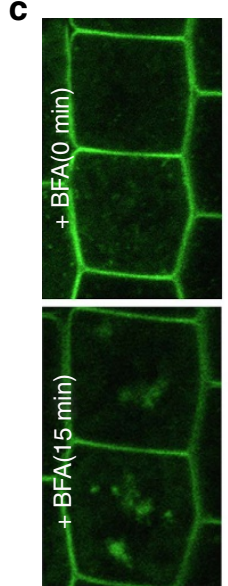

NPF3-YFP

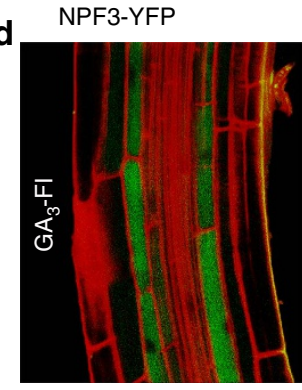

$-B F A$

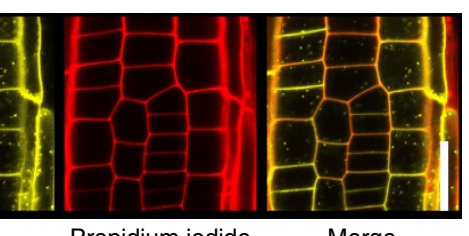

Propidium iodide

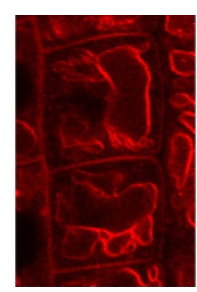

FM4-64
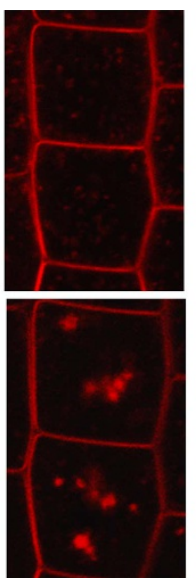

FM4-64

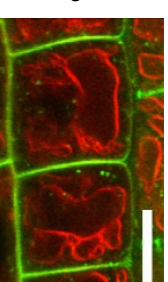

Merge
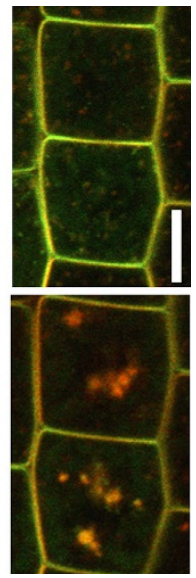

Merge

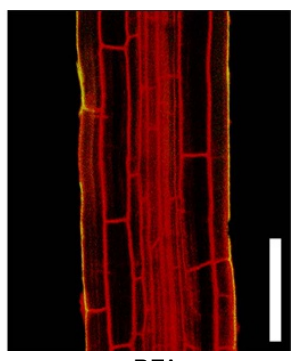

$+\mathrm{BFA}$ e
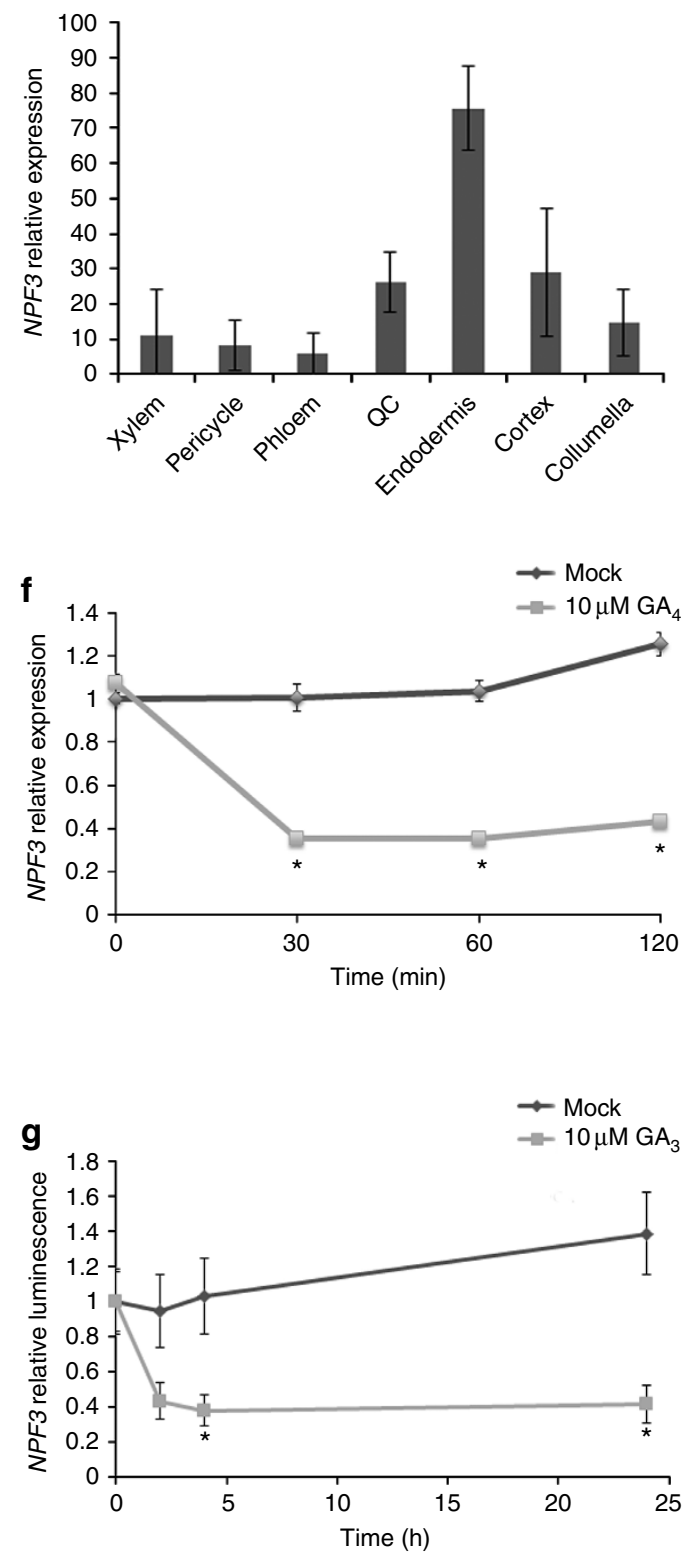

Figure 2 | NPF3 is targeted to the plasma membrane in a BFA-dependent manner and is transcriptionally repressed by GA. (a) Root confocal microscopy images of NPF3-YFP localization counterstained with Propidium lodide. Bar, $20 \mu \mathrm{m}$. (b) Confocal microscopy images of root epidermis cells from 7-day-old p35S:NPF3-YFP seedlings. Vacuolar tonoplast was pulse-stained for 15 min with FM4-64 (2 $\mu$ M), transferred to dye free liquid media for $60 \mathrm{~min}$, and imaged subsequently. Bar, $10 \mu \mathrm{m}$. (c) p35S:NPF3-YFP plants treated for 0 and 15 min with the trafficking inhibitor Brefeldin A (BFA) ( $50 \mu \mathrm{M}$ ). Bar, $10 \mu \mathrm{m}$. (d) Confocal images of WT roots immersed in $\mathrm{GA}_{3}-\mathrm{Fl}$ ( $5 \mu \mathrm{M} 3 \mathrm{~h}$ treatment) with and without BFA treatment ( $50 \mu \mathrm{M} 14 \mathrm{~h}$ treatment). Bar, $50 \mu \mathrm{m}$. (e) NPF3 expression levels derived from root cell type-specific protoplasts Brady et al. ${ }^{40}$. (f) NPF3 relative expression in response to $10 \mu \mathrm{M}$ GA 4 treatment. Seedlings were pretreated with paclo $(5 \mu \mathrm{M}, 6$ days). RNA levels were quantified by qRT-PCR with ACTIN8 as a reference gene. Values are mean \pm s.d. $(n=3)$. (g) Luminescence intensity of pNPF3:LUC seedlings treated with mock or $10 \mu M \mathrm{GA}_{3}$ for $0,2,4$ and $24 \mathrm{~h}$. Values are mean \pm s.e. $(n=24)$. * Significantly different relative to respective mock at $P \leq 0.001$ by Student's $t$-test.

with $10 \mu \mathrm{M} \mathrm{GA}_{3}$ for 1-24h showed reduced LUC signal (Fig. 2g). These results indicate that high levels of GA repress NPF3 expression and thus inhibit GA uptake. Published data show that NPF3 is induced by $\mathrm{ABA}(10 \mu \mathrm{M}, 3 \mathrm{~h})$ and salt stress $(150 \mathrm{mM}, 12 \mathrm{~h})^{43-45}$. These results were reproduced for $\mathrm{ABA}$ in our quantitative PCR experiments (Supplementary Fig. 4a). Accordingly, we show that $\mathrm{GA}_{3}-\mathrm{Fl}$ accumulation in the endodermis is induced by $\mathrm{ABA}$ and $\mathrm{NaCl}$ treatments in a concentration-dependent manner (Supplementary Fig. 4b). The $\mathrm{ABA}$ induced $\mathrm{GA}_{3}$-Fl uptake into the elongating endodermal cells does not take place in $n p f 3-1$ mutant, and therefore is NPF3 dependent (Supplementary Fig. 4b).

NPF3 loss and gain-of-function growth phenotypes. The fluorescent GA experiments suggested that NPF3 is involved in bioactive GA transport in the root. To study NPF3 regulation in GA-mediated plant growth and development, we compared WT, NPF3 loss of function and overexpression lines ( $p 35 S: N P F 3-Y F P$ ), assessing GA-mediated traits such as germination, root and shoot 
elongation and flowering time. Both $n p f 3-1$ and $n p f 3-2$ mutants lines were like the WT with respect to all these traits (Fig. 3a,b) despite their failure to accumulate the fluorescently tagged hormone. The lack of a mutant phenotype in the $n p f 3$ mutants despite the strong effect on GA-Fl uptake is puzzling. It is possible that there are alternative functionally redundant GA transporters that compensate in the absence of NPF3. This hypothesis is supported by functional transport experiments described below (Fig. 4e,f, Supplementary Fig. 6).
In contrast, p35S:NPF3-YFP plants exhibit delayed germination, decreased hypocotyl growth, and a strong reduction in root and shoot growth (Fig. 3a,b, Supplementary Fig. 5). These defects are similar to those seen in GA-deficient plants ${ }^{46,47}$. The growth inhibition caused by NPF3 overexpression might be caused by the retention of GA at sites of synthesis, thus preventing movement of GA to key growth sites. If this is correct, one might expect stronger accumulation of GA-Fl in the outer layers (GA-Fl is applied exogenously) for p35S:NPF3-YFP

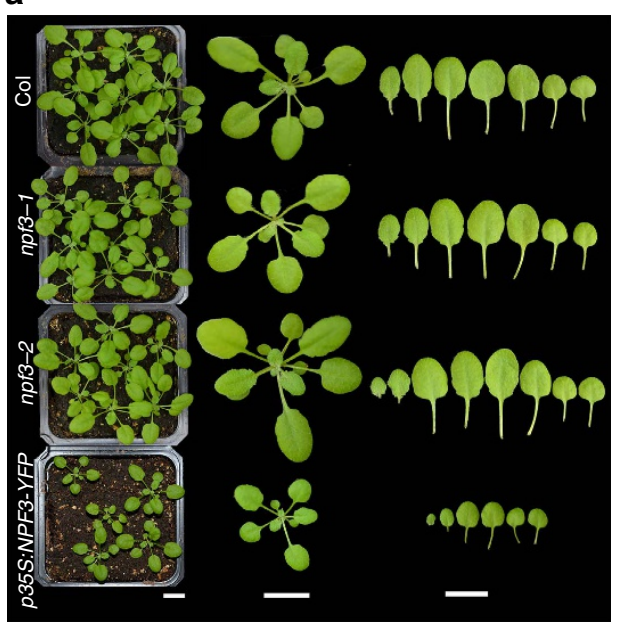

b
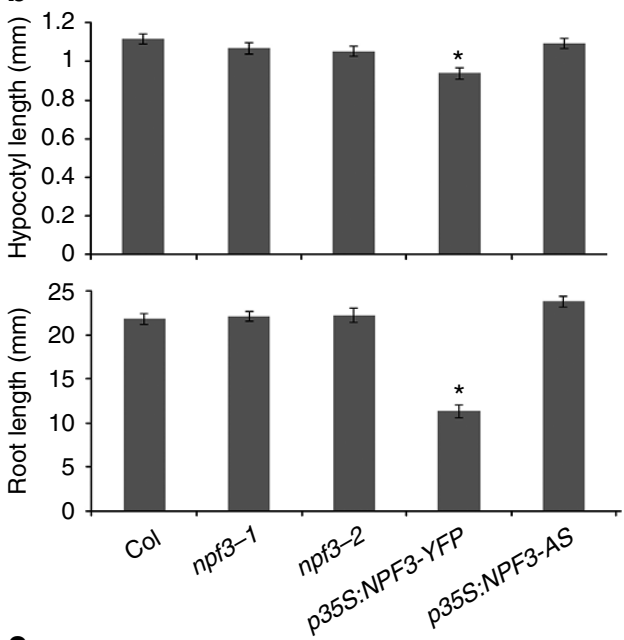

C

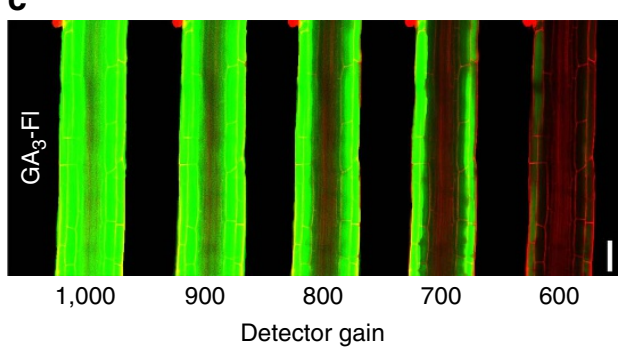

d

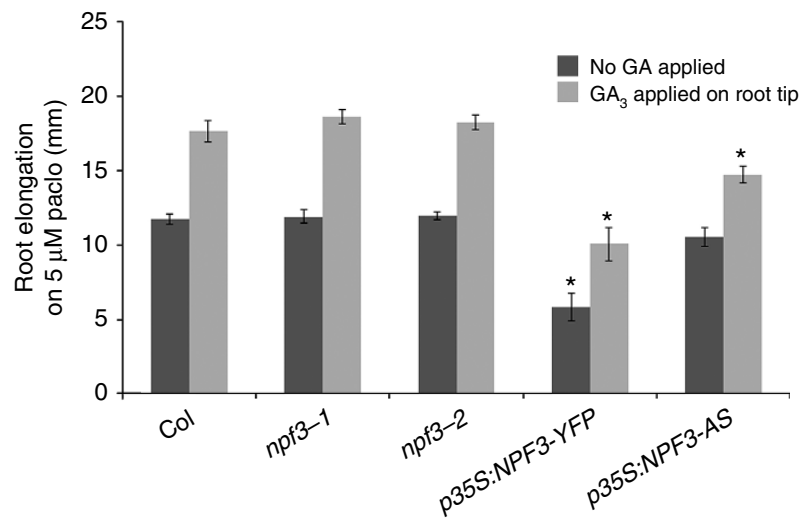

e
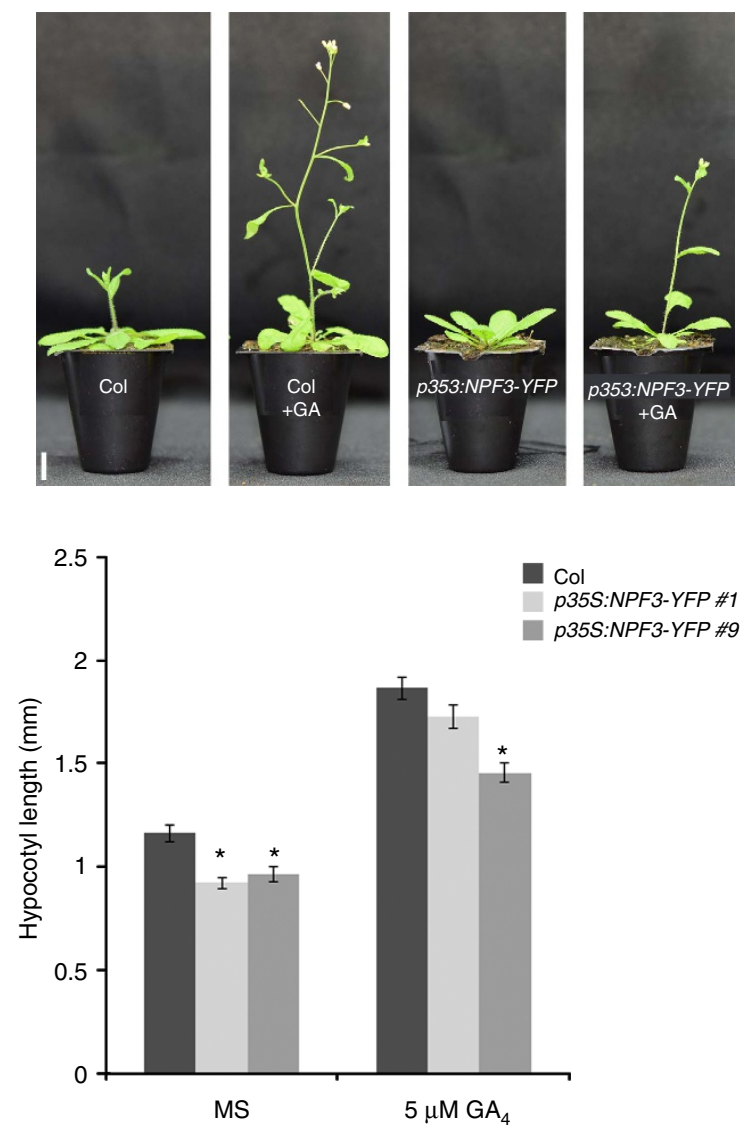

Figure 3 | Overexpression of NPF3 mimics GA deficiency. (a) Phenotypes of 3 week-old npf3 mutants and p35S:NPF3-YFP lines compared with WT (Col-0). Bar, $1 \mathrm{~cm}$. (b) Quantification of root and hypocotyl length of 7-day-old seedlings growing on MS media. Values are means \pm s.e. of 11 seedlings per genotype in two independent experiments $n=22$. (c) $\mathrm{GA}_{3}-\mathrm{Fl}$ accumulation in p35S:NPF3-YFP plants under reduced detector gains, $(5 \mu \mathrm{M} \mathrm{GA}-\mathrm{Fl}, 1.5 \mathrm{~h}$ treatment). Bar, $50 \mu \mathrm{m}$. (d) Graph presenting root elongation on $5 \mu \mathrm{M}$ paclo, and response to exogenously applied $5 \mu \mathrm{M} G \mathrm{~A}_{3}$. Shown are means \pm s.e. of at least 11 seedlings per genotype. The experiment was repeated three times. (e) Representative images of 4 week-old WT and p35S:NPF3-YFP plants grown on soil with or without $10 \mu \mathrm{M} \mathrm{GA}$ spraying, $n=12$, bar, $1 \mathrm{~cm}$. (f) Hypocotyl length of 2 independent $p 35 \mathrm{~S}$ :NPF3-YFP lines and WT (Col-0) seedlings germinated and grown on MS with or without $5 \mu \mathrm{M} \mathrm{GA}_{4}$. Values are means \pm s.e. of 13 seedlings per genotype. ${ }^{*}$ Significantly different relative to respective WT at $P \leq 0.001$ by Student $t$-test. 
roots. Indeed, $\mathrm{GA}_{3}-\mathrm{Fl}$ accumulated at higher levels in the epidermal layer compared with the inner layers (Fig. 3c), suggesting that the epidermal layer has imported $\mathrm{GA}_{3}-\mathrm{Fl}$ and trapped the molecule in the cell in a NPF3-dependent manner. In addition, expression of the GA2ox1 gene, encoding a GA-inactivating enzyme, was transiently reduced in response to GA compared with WT (Supplementary Fig. 5c). The striking ectopic GA-Fl accumulation in additional cells of $p 35 S: N P F 3-Y F P$ seedlings, accompanied by GA-related developmental defects observed in these lines, support a role for NPF3 in GA responses.

To further understand the role of NPF3 in GA-mediated root growth, we examined the response of NPF3 loss- and gain-of-function lines to paclo and applied GA. Paclo is an inhibitor of GA synthesis that causes reduced root growth that can be rescued by applying exogenous bioactive GA. The $n p f 3$ mutants responded to paclo and applied GA like WT. In comparison, p35S:NPF3-YFP and p35S:NPF3-antisense plants showed a reduced growth response to GA. (Fig. 3d). The response of $p 35 S: N P F 3-Y F P$ seedlings to GA is consistent with the hypothesis that ectopic expression of NPF3 inhibits bioactive GA movement to key growth sites. p35S:NPF3-antisense lines showed reduced NPF3 expression (Supplementary Fig. 1d), while no additional change in expression level could be detected in other family members that were shown to transport GA in yeast assays ${ }^{33}$, and are expressed in the root tip (Supplementary Figs 5d, 6b).

Long-term treatment of p35S:NPF3-YFP lines with GA might compensate for the altered distribution of endogenous hormone. In agreement, long-term (10 and 21 days) GA treatment of the p35S:NPF3-YFP line promoted shoot growth and flowering, largely rescuing the hypocotyl elongation, (depending on NPF3 overexpression strong/weak line; Fig. 3e,f), while partially rescuing the root growth phenotype (once a day for 4 days, $1 \mu \mathrm{l}$ application, $5 \mu \mathrm{M} \mathrm{GA}_{3}$ to root tip, in paclo background; Fig. $3 \mathrm{~d}$ ). To investigate whether NPF3 promotes GA activity as opposed to GA storage and degradation, p35S:NPF3-YFP seedlings were grown on increasing concentrations of GA. While WT plants showed reduced growth and yellow shoot colour on high GA concentration $(50 \mu \mathrm{M})$, p35S:NPF3-YFP showed similar phenotypes when grown on $15 \mu \mathrm{M}$ GA (Supplementary Fig. 5e). This result suggests that NPF3 promotes accumulation of GA in GA responding cells and that NPF3 is involved in GA-mediated plant growth and development.

Recent work showed that various NPF proteins can transport $\mathrm{ABA}$ and nitrate ${ }^{26}$. To test the role of NPF3 in ABA and nitrate response, we tested NPF3 overexpression lines, T-DNA mutants and antisense lines on ABA and nitrate assays. We could not detect any difference to the WT in response to nitrate for any of the tested lines (Supplementary Fig. 5g-h). However, overexpression of $N P F 3$ resulted in a significant reduction in germination with and without ABA treatment (Supplementary Fig. 5i). Interestingly, we observed a small but significant decrease in germination in the $n p f 3-2$ mutant allele and $N P F 3$ antisense line at high ABA concentrations ( $3 \mu \mathrm{M}$; Supplementary Fig. $5 \mathrm{i})$. $N P F 3$ overexpression but not $n p f 3$ loss-of-function lines showed significant root response to ABA compared with WT (Supplementary Fig. 5j). It is, therefore, likely that the strong NPF3 overexpression phenotype is driven by the mislocalization of both hormones. These results together with the results showing that ABA induces NPF3 expression and GA-Fl accumulation in the elongating endodermal cells, suggest that NPF3 may be involved in ABA localization and response.

NPF3 is a GA transporter. Our results indicate that NPF3 transports GA-Fl in planta. To elucidate the mechanisms underlying GA transport by NPF3, we used the Xenopus oocyte expression system. Uptake experiments showed that NPF3 mediated $\mathrm{GA}_{3}-\mathrm{Fl}$ uptake into oocytes (Fig. 4a), confirming that NPF3 is a GA-Fl importer. In contrast, the glucosinolate transporter 2 (NPF2.11/GTR2) and non-expressing control oocytes did not import $\mathrm{GA}_{3}-\mathrm{Fl}$ into oocytes (Fig. 4a). Oocytes expressing NPF3 exposed to $100 \mu \mathrm{M} \mathrm{GA}_{3}$ at $\mathrm{pH} 5$ ( apoplastic $\mathrm{pH}$ conditions) showed a 19.1-fold increase in $\mathrm{GA}_{3}$ uptake compared with non-injected oocytes, and 10-fold higher than GTR2 uptake (Fig. 4b), indicating that NPF3 can transport native GA. To determine whether NPF3 transports other active GAs present in plants, we exposed NPF3-expressing oocytes to $100 \mu \mathrm{M} \mathrm{GA} A_{1}, \mathrm{GA}_{3}$ or $\mathrm{GA}_{4}$ at $\mathrm{pH} 5.5$ and 7.5. Oocytes expressing NPF3 accumulated $\sim 14$ fold higher $\mathrm{GA}_{4}$ levels compared to $\mathrm{GA}_{3}$, and $\sim 7$ fold higher levels compared to $\mathrm{GA}_{1}$ at $\mathrm{pH} 5.5$ (Fig. 4c). This indicates that $\mathrm{GA}_{4}$, which is the active endogenous GA in Arabidopsis is the preferred GA substrate of NPF3 (Fig. 4c). Most NPF importers characterized to date are proton symporters that utilize the inwardly directed electrochemical proton gradient $\left(\Delta \mu \mathrm{H}^{+}\right)$ between the plant apoplast $(\sim \mathrm{pH} 5)$ and cytoplasm $(\sim \mathrm{pH} 7.5)$ to drive import of substrates ${ }^{48}$. Oocytes expressing NPF3 showed an increased uptake of $\mathrm{GA}_{4}, \mathrm{GA}_{3}$ and $\mathrm{GA}_{1}$ at $\mathrm{pH} 5.5$ compared with $\mathrm{pH} 7.5$ (Fig. 4c). This indicates that transport by NPF3 is dependent on the $\mathrm{pH}$ gradient. In agreement, seedlings exposed to $\mathrm{pH} 7.5$ media showed reduced accumulation of $\mathrm{GA}_{3}-\mathrm{Fl}$ in the root elongation zone compared with roots growing in $\mathrm{pH} 5.7$ media (Fig. 4d,e).

We exposed NPF3-expressing oocytes to increasing concentrations of $\mathrm{GA}_{4}$ and calculated the $\mathrm{GA}_{4}$ transported by NPF3 into the oocytes following $60 \mathrm{~min}$ incubation by subtracting uptake in non-injected oocytes (diffusion). This yielded a saturation curve from which we estimate an apparent $K_{\mathrm{m}}$ of NPF3 towards $\mathrm{GA}_{4}$ of $0.5 \mathrm{mM}$ (Supplementary Fig. 6a). Kinetic uptake assays of weak acids are, however, notoriously difficult to interpret. The propensity of weak acids to diffuse across cellular membranes at acidic $\mathrm{pH}$ and the cumulative nature of the uptake assays makes it difficult to accurately estimate the apparent $K_{\mathrm{m}}$. As an example, we previously estimated the apparent $K_{\mathrm{m}}$ value for glucosinolate uptake by GTR2 using liquid chromatography mass spectrometry (LC-MS) and electrophysiology-based uptake assays. LC-MS-based uptake assays estimated a $K_{\mathrm{m}}$ value that was approximately fivefold higher (unpublished data) compared with the more accurate value determined by electrophysiology ${ }^{49}$. We thus judge that the $K_{\mathrm{m}}$ of NPF3 towards $\mathrm{GA}_{4}$ is likely to be an overestimation.

It was recently reported that a large number of NPF transporters promote GA uptake in yeast when utilizing a GA-dependent yeast two-hybrid protein-protein interaction approach ${ }^{33}$. Besides NPF3, six of the apparent GA-importing $N P F$ genes were expressed in different tissues in the root tip. These include NPF2.3, NPF2.10/GTR1, NPF4.1/AIT3, NPF4.2/ AIT4, NPF5.6 and NPF5.7 (Supplementary Fig. 6b). Using the Xenopus oocyte system, we compared the ability of NPF3 and the three transporters NPF2.10, NPF4.1 and NPF5.7 to import $\mathrm{GA}_{3}-\mathrm{Fl}$ and $\mathrm{GA}_{4}$-FI. Interestingly, NPF3 displayed transport activity towards $\mathrm{GA}_{3}-\mathrm{Fl}$ and $\mathrm{GA}_{4}$-Fl whereas the other genes imported neither of the labelled GA species significantly above levels detected in control oocytes (Fig. 4e). We then tested the ability of the four transporters to import non-conjugated $\mathrm{GA}_{3}$ and $\mathrm{GA}_{4}$. In contrast to the qualitative evidence for GA import provided previously ${ }^{33}$, only NPF3 and NPF4.1 imported $\mathrm{GA}_{3}$ and $\mathrm{GA}_{4}$ into the oocytes to levels significantly above those found in control oocytes (Fig. 4f). This indicates that the number of putative GA transporters suggested previously ${ }^{33,34}$ may be an overestimation. Interestingly, NPF4.1 imported $\mathrm{GA}_{3}$, (exogenous to Arabidopsis) to fivefold higher levels compared with NPF3, 
a

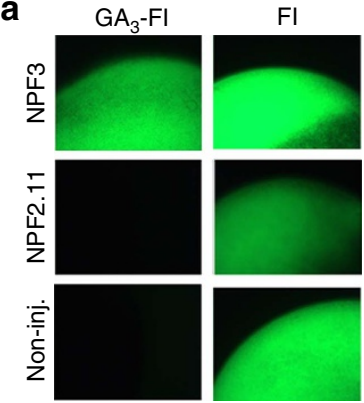

d

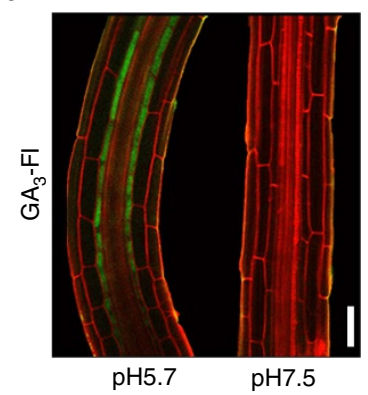

f

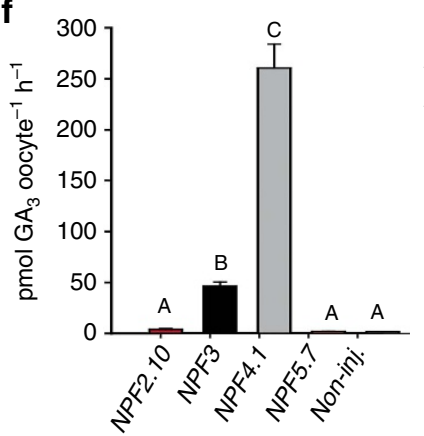

b
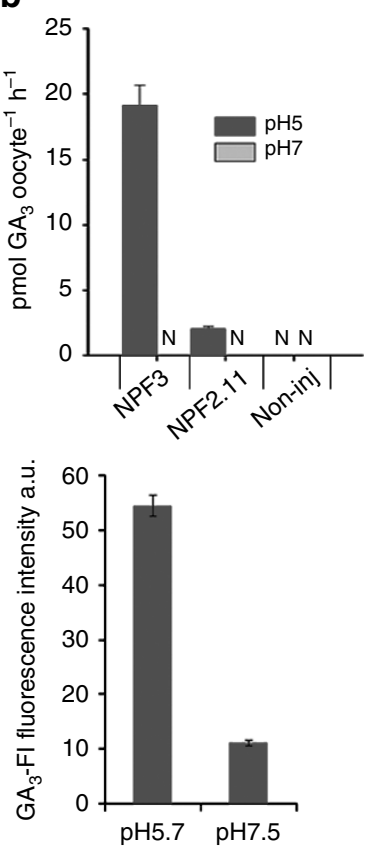

C

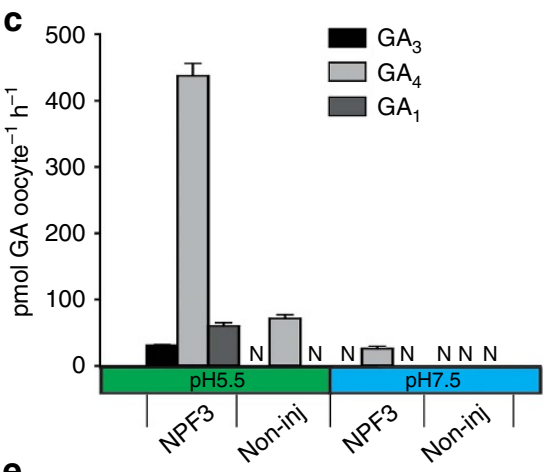

e
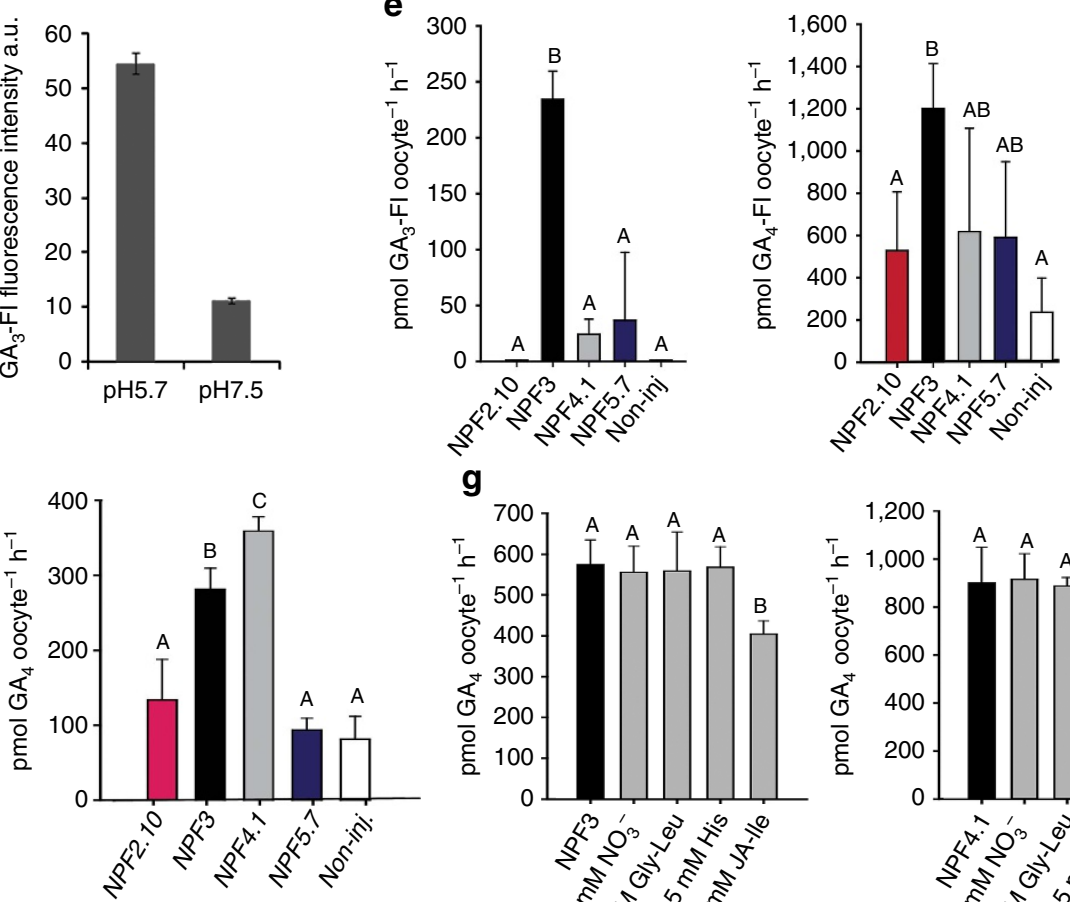

g
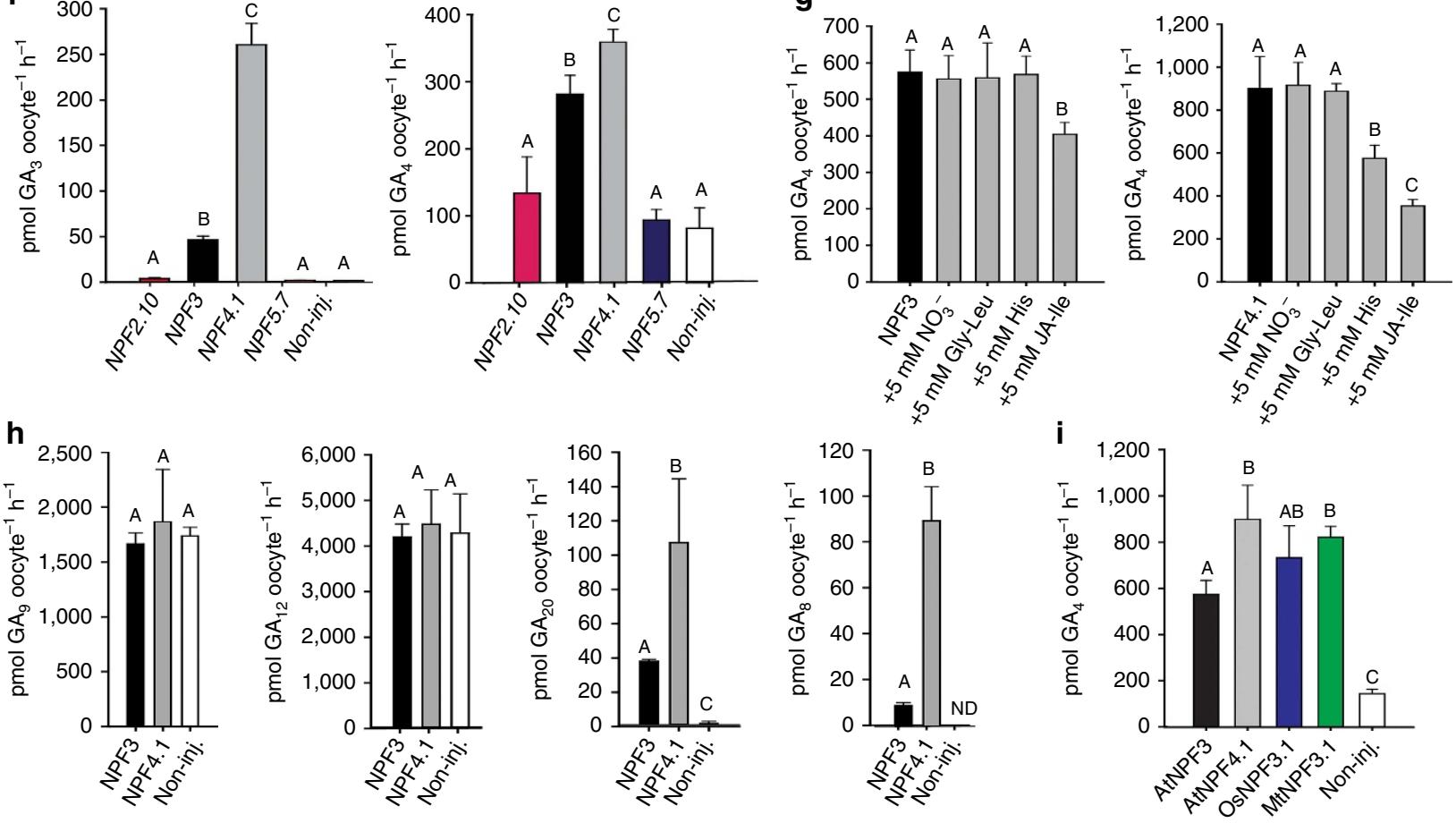

Figure 4 | NPF3 is a GA transporter in Xenopus laevis oocytes. (a) Uptake of GA $A_{3}-F$ l and fluorescein by NPF3, NPF2.11 (GTR2) and non-injected oocytes. Oocytes were incubated for $30 \mathrm{~min}$ in $100 \mu \mathrm{M} \mathrm{GA}-\mathrm{Fl}(\mathrm{pH} 5)$. Picture shows a representative oocyte from 3 oocytes. (b) Uptake of GA 3 by NPF3, NPF2.11 (GTR2) and non-injected oocytes at pH5 and pH7. Oocytes were incubated for $1 \mathrm{~h}$ in $100 \mu \mathrm{M} \mathrm{GA} 3$ (pH5 or pH7) ( $n=3$ ). N: below detection limit.

(c) Bioactive $\mathrm{GA}_{1}, \mathrm{GA}_{3}$ and $\mathrm{GA}_{4}$ uptake at $\mathrm{pH} 5.5$ and pH 7.5 by NPF3. NPF3-expressing or non-injected oocytes were incubated for $1 \mathrm{~h}$ in $100 \mu \mathrm{M}$ with the indicated GAs $(n=3)$. N: below detection limit. (d) Confocal images of WT root elongation zone immersed in $\mathrm{GA}_{3}-\mathrm{Fl}(5 \mu \mathrm{M}, 3 \mathrm{~h})$ in indicated pHs. Right graph: quantification of $\mathrm{GA}_{3}-\mathrm{Fl}$ fluorescence intensity. Presented are averages \pm s.e. roots per genotype and 26 sampling points per root $(n=104)$.

Bar, $50 \mu \mathrm{m}$. (e) Uptake of $\mathrm{GA}_{3}-\mathrm{Fl}$ and $\mathrm{GA}_{4}-\mathrm{Fl}$ by oocytes expressing the indicated endodermis expressed NPFs $(n=4)$. (f) Uptake of GA $\mathrm{A}_{3}$ and $\mathrm{GA}_{4}$ by oocytes expressing the indicated endodermis expressed NPFs $(n=4)$. (g) Competition of $\mathrm{GA}_{4}$ uptake mediated by NPF3 and NPF4.1 (AIT3) expressing oocytes. Oocytes expressing either NPF3 or NPF4.1 were exposed to $300 \mu \mathrm{M} \mathrm{GA}_{4}$ alone or $300 \mu \mathrm{M} \mathrm{GA}_{4}$ together with either $5 \mathrm{mM} \mathrm{NO}_{3}^{-}, 5 \mathrm{mM}$ dipeptide (Gly-Leu), $5 \mathrm{mM}$ histidine (His) or $5 \mathrm{mM}$ JA-isoleucine (JA-lle; $n=5$ ). (h) Uptake of indicated GA precursors and catabolite mediated by NPF3 and NPF4.1 (AIT3) expressing and non-injected oocytes. Oocytes were incubated for $1 \mathrm{~h}$ in $100 \mu \mathrm{M}$ of the indicated GA (at pH5) ( $n=5$ ). (i) Uptake of GA 4 by Oryza sativa and Medicago truncatula NPF3.1 orthologs as defined by ref. 26. Oocytes expressing A. thaliana NPF3 (AtNPF3.1), O. sativa NPF3.1 (OsNPF3.1) or M. truncatula NPF3.1 (MtNPF3.1) or non-injected oocytes were incubated for $1 \mathrm{~h}$ in $300 \mu \mathrm{M} \mathrm{GA}_{4}$ at pH5 $(n=5)$. In all graphs: Error bars are s.d. unless indicated otherwise. Groups are determined by one-way analysis of variance and $(P<0.05)$. non-inj., non-injected. 
whereas import of $\mathrm{GA}_{4}$ (endogenous to Arabidopsis) was similar between the two proteins (Fig. 4f). Taken together, these results highlight that before identification and characterization of the transporters, caution must be taken when using fluorescent labelling to follow phytohormone mobility in planta. In this study, application of GA-Fl helped us identify NPF3 as a putative GA transporter but also indicated that NPF3 was solely responsible for GA accumulation in root endodermis. In fact, biochemical characterization shows that NPF4.1 likely acts redundantly and may compensate for NPF3 loss of function in planta.

As the NPF family of transporters possesses a remarkably wide substrate specificity ${ }^{26}$, we performed competition experiments using known substrates of the family. $\mathrm{GA}_{4}$ import by NPF3 and NPF4.1 was competed with 15 -fold excess concentration of $\mathrm{NO}_{3}^{-}$(ref. 50), dipeptide (Gly-Leu) ${ }^{51}$, histidine $\mathrm{s}^{52}$ or JA-Ile ${ }^{33}$. NPF3-mediated transport of $\mathrm{GA}_{4}$ was not significantly affected by excess nitrate, dipeptide nor histidine and was weakly affected by JA-Ile. In comparison, NPF4.1-mediated uptake of $\mathrm{GA}_{4}$ was weakly affected by excess histidine whereas JA-Ile strongly inhibited $\mathrm{GA}_{4}$ uptake (Fig. 4g, Supplementary Fig. 6c-d). These observations suggest that NPF3 is predominantly a GA transporter. In comparison, our and previous studies suggest that NPF4.1 is a multi-specific transporter capable of importing several structurally unrelated phytohormones including ABA, GA and JA-Ile.

Recent work has identified the GA-intermediate $\mathrm{GA}_{12}$ as a long-distance transported form of inactive GA in Arabidopsis ${ }^{20}$ and the GA-intermediate $\mathrm{GA}_{20}$ as a transported form in Pisum sativum $^{53}$. Consequently, we tested whether NPF3 and NPF4.1 transported selected commercially available intermediates $\left(\mathrm{GA}_{9}, \mathrm{GA}_{12}\right.$ and $\left.\mathrm{GA}_{20}\right)$ and the catabolite $\mathrm{GA}_{8}$ of the GA biosynthetic pathway. At $\mathrm{pH} 5, \mathrm{GA}_{9}$ and $\mathrm{GA}_{12}$ precursors of $\mathrm{GA}_{4}$ accumulated to very high levels in oocytes and to the same extent in NPF3- and NPF4.1-expressing and non-injected oocytes due to diffusion (Fig. 4h). We were therefore not able to determine whether NPF3 and NPF4.1 transport these two intermediates. In comparison, $\mathrm{GA}_{20}$ accumulated to detectable levels in oocytes expressing NPF3 and NPF4.1, but to barely detectable levels in non-injected oocytes (Fig. 4h). Similarly, $\mathrm{GA}_{8}$, catabolite of $\mathrm{GA}_{1}$, accumulated to detectable levels in oocytes expressing NPF3 and NPF4.1, but below detection levels in non-injected oocytes (Fig. 4h). This suggests that NPF3 is able to transport $\mathrm{GA}_{20}$ in Arabidopsis. Interestingly, transport of the $\mathrm{GA}_{8}$ catabolite by NPF3- and NPF4.1-expressing oocytes indicated that intercellular transport of GA catabolites may occur in Arabidopsis.

Phylogenetic analysis suggests that NPF3 is conserved in all plant lineages with orthologs sharing a high degree of identity ${ }^{26}$. We tested $\mathrm{GA}_{4}$ transport capability of the NPF3 orthologs in the grass Oryza sativa (OsNPF3.1) and the legume Medicago truncatula (MtNPF3.1) ${ }^{26}$. OsNPF3.1 and MtNPF3.1 imported $\mathrm{GA}_{4}$ into oocytes to similar levels as AtNPF3, which indicates functional conservation of GA transport activity in orthologous NPF3 transporters (Fig. 4i).

Finally, as several members of the NPF family have been shown to transport ABA and auxin ${ }^{12,30,33,34}$, we tested NPF3 transport activity towards these plant hormones at $\mathrm{pH} 5.5$ and $\mathrm{pH} 7.5$. NPF3 accumulated $\mathrm{GA}_{4}$ and $\mathrm{ABA}$ in oocytes to comparable levels (Supplementary Fig. 6f). Dual GA/ABA substrate specificity was also reported for NPF4.1, previously identified as an ABA transporter also permeable for $\mathrm{GA}_{3}$ (ref. 12). This suggests that $\mathrm{ABA}$ and GA transport may be linked through the dual specificity of several NPF transporters. Uptake of the auxin indole-3-acetic acid by NPF3 was similar to non-injected control oocytes (Supplementary Fig. 6e). Thus, it is possible that NPF3 in our experimental setup plays a particularly important role for GA-Fl uptake, but acts redundantly with at least, NPF4.1/AIT3 or other GA transporters with respect to transport of non-conjugated $\mathrm{ABA}$ and GA. Altogether, our results show that NPF3 is a GA transporter that is functionally conserved across dicot and monocots and that appears functionally redundant with additional GA transporters in the elongating root endodermis.

\section{Discussion}

GAs are fundamental for many aspects of plant growth and development. Here we shed light on the cellular mechanisms regulating GA transport in the root by revealing that NPF3 is a GA importer. An important question that this study could not fully address is whether NPF3 regulates GA cellular influx to promote GA activity or to inhibit GA response by GA degradation and/or storage. However, the fact that the endodermis is known to have an important role in GA response $\mathrm{e}^{54,55}$, and NPF3 overexpression results in hypersensitivity to high levels of GA suggests that NPF3 is functioning to promote GA response. Although this study reveals that NPF3 can transport GA in vitro, and GA-Fl in the root, the complete GA transport mechanism is not clear. Since cytosolic pH 7.5 is driving GA de-protonation through the ion trap mechanism, the majority of $\mathrm{GA}_{4}$ is expected to be captured, with the limited ability to move from cell to cell ${ }^{22}$. The presence of GA exporters might explain how GA moves locally at the tissue or cellular level; however, these are yet to be discovered. It is possible that putative GA efflux carriers act redundantly and are therefore difficult to identify in genetic screens.

The NPF family of proton-coupled transporters is involved in nitrogen assimilation in eukaryotes and bacteria. In most plant species, NPF members have evolved to transport nitrate as well as additional specialized metabolites and hormones. This complexity makes it difficult to assess the biological role of the NPF proteins. How a transporter recognizes such different metabolites and hormones is an intriguing question. An interesting example of such diversity is the dual-affinity-specificity nitrate/auxin transporter NRT1.1 (ref. 30). The dual sensor/transceptor model proposes that $\mathrm{NO}_{3}^{-}$sensing function of NRT1.1 is due to its dual $\mathrm{NO}_{3}^{-}$/auxin transport activity and that the $\mathrm{NO}_{3}^{-}$signal transduced by NRT1.1 is an $\mathrm{NO}_{3}^{-}$-dependent modification of auxin transport in lateral root development ${ }^{30}$. On top of the multisubstrate specificity, this and other recent studies suggest that several NPFs can transport $\mathrm{GA}^{33,34}$. These results present an additional level of regulation of the GA response. It is intriguing to consider how NPF3 transports two antagonistic hormones, GA and ABA (possibly with different affinities), while NPF3 is induced by $\mathrm{ABA}$ and repressed by GA. We hypothesize that differences in spatiotemporal expression pattern as well as differences in subcellular localization and transport affinity among the NPF transporters towards GAs might explain the complex specificity and redundancy of GA transport. We expect future studies to dissect the complex network of multisubstrate specificity versus functional redundancy towards the same substrate that have evolved in the NPF family.

\section{Methods}

Plant material and growth conditions. All Arabidopsis thaliana lines used in this work are in Col-0 background. T-DNA insertion mutants were obtained from the Arabidopsis Biological Resource Center and Nottingham Arabidopsis Stock Centre. Homozygous mutants were selected by PCR using primers listed in Supplementary Table 1 .

Seeds were plated on medium containing $0.5 \times$ Murashige-Skoog (MS) medium, $1 \%$ sucrose and $0.8 \%$ agar on vertical plates, stratified for 2 days at $4{ }^{\circ} \mathrm{C}$ then transferred to growth chambers (Percival CU41L5) at $21^{\circ} \mathrm{C}, 100 \mu \mathrm{E} \mathrm{m}^{-2} \mathrm{~S}^{-1}$ light intensity under long day light (16 h light/8 h dark). 
Cloning of NPF3 overexpression and reporter lines. NPF3 was amplified with primer combinations listed in Supplementary Table 2, cloned into pENTR/D-TOPO (Invitrogen K2400) and subsequently cloned into binary destination vectors using LR Gateway reaction (Invitrogen 11791). We have examined the phenotype and YFP fluorescence for 13 independent NPF3-YFP lines (Supplementary Fig. 5f). The lines were partially silenced at the $T_{3}$ generation. We continued with two lines that showed reduced silencing and high NPF3 RNA level (line \#1 and 9; Supplementary Figs 1d and 5). All experiments were carried out with p35S:NPF3-YFP\#9 unless otherwise indicated.

Hormone and inhibitor application. Chemicals were supplied to the agar medium at concentrations as indicated for each experiment in figure legends (starting from $10 \mathrm{mM}$ stock solutions). Seedlings were placed on agar plates and roots were uniformly supplemented with chemicals. GA-Fl $(5 \mu \mathrm{M})$ was applied in liquid MS media. Time points and chemicals concentrations are indicated for each experiment in the figure legend.

Imaging and analysis. Seedlings were stained in $10 \mathrm{mgl}^{-1}$ propidium iodide (PI) for $1 \mathrm{~min}$, rinsed and mounted in water. Seedlings were imaged on a laser scanning confocal microscope (Zeiss LSM 780 inverted microscope), with argon laser set at $488 \mathrm{~nm}$ for fluorescein excitation, $561 \mathrm{~nm}$ laser for PI excitation. Emission filters used were $493-548 \mathrm{~nm}$ filter for fluorescein derivatives, and $583-718 \mathrm{~nm}$ filter for PI emission. Image analysis and signal quantification were done with the measurement function of ZEN lite 2012 software. The number of quantified biological repeats and sampling points is indicated for each graph in figure legends.

Statistical analysis. Two-tailed Student's $t$-test was performed whenever two groups were compared. Statistical significance was determined at $P<0.001$ unless otherwise indicated.

Luciferase reporter assay. Transgenic lines expressing luciferase under NPF3 promotor of $2 \mathrm{~Kb}$ upstream of the ATG start codon, designated pNPF3:LUC, were grown for 10 days on MS horizontal plates and sprayed with solution containing $1 \mathrm{mM}$ potassium luciferin (Promega E1601) and 2\% Triton X-100. Plants were assayed for luciferase activity $14 \mathrm{~h}$ after spraying using BioSpace PhotonIMAGER. Plates were then flooded with liquid MS with or without $10 \mu \mathrm{M} \mathrm{GA}_{3}$ and assayed again at indicated times. Luminescence was quantified using M3Vision Software.

Phenotype characterization. To assess germination, seeds were plated on horizontal MS plates, germination rate determined as seed coat rupture after 2 days scored under a Zeiss Stemi 2000-C stereo microscope.

For root and hypocotyl length measurements, seedlings were imaged using Zeiss Stemi 2000-C stereo microscope and measured using ImageJ software (http://rsbweb.nih.gov/ij/index.html).

To assess etiolation, seedlings of indicated lines were sown on sucrose free MS, exposed to $100 \mu \mathrm{E} \mathrm{m}^{-2} \mathrm{~S}^{-1}$ fluorescent light for $4 \mathrm{~h}$, followed by 3 days at the dark. Hypocotyl length quantified as described above.

For root GA response assays, seeds were germinated on MS were transferred to $5 \mu \mathrm{M}$ paclo after 4 days. On the next day, root length was marked. $1 \mu \mathrm{l}$ of $5 \mu \mathrm{M} \mathrm{GA}_{3}$ diluted in water was applied to root tips for the three subsequent days. Roots were imaged and measured on day 10.

Quantitative RT-PCR. For all experiments except results presented in Fig. $2 \mathrm{f}$ and Supplementary Fig. 5c, total RNA was isolated from the indicated plant materials using RNeasy Plant Mini Kit (QIAGN 74,904). DNA was removed by RQ1 RNasefree DNase (Promega M6101). Total RNA $(2 \mu \mathrm{g})$ converted to complementary DNA (cDNA) using M-MLV Reverse Transcriptase (Promega M1701) with oligo(dT) 15 primer according to manufacturer protocols. Quantitative RT-PCR was performed with $40 \mathrm{ng}$ cDNA in a final volume of $10 \mu \mathrm{l}$ with Fast SYBR Green Master Mix (ABI 4385612) using Step One Plus System and software (ABI). The reaction conditions included 40 amplification cycles, $\left(3 \mathrm{~s}\right.$ at $95^{\circ} \mathrm{C} ; 30 \mathrm{~s}$ at $60^{\circ} \mathrm{C}$ ). Three technical repeats were performed for each cDNA sample, and at least three biological repeats were used for each treatment. The relative quantification was calculated with the $\triangle \triangle \mathrm{Ct}$ method, $P P 2 A$ used as reference gene. Primers are specified in Supplementary Table 3. For results presented in Fig. $2 \mathrm{f}$ and Supplementary Fig. $5 \mathrm{c}$, plant materials were transferred to $5 \mu \mathrm{M}$ paclo following germination on MS plates. After 6 additional days, seedlings were treated with $10 \mu \mathrm{M} \mathrm{GA}_{4}$ in liquid MS for the indicated time periods. Total RNA was isolated from plants using NucleoSpin RNA plant kit and DNA was removed by an on-column treatment with rDNase (Macherey-Nagel, Düren, Germany). $2 \mu \mathrm{g}$ of total RNA was subsequently reverse transcribed with M-MuLV Reverse Transcriptase (Fermentas, St Leon-Rot, Germany) using an oligo(dT) primer. The cDNA equivalent of 30-50 ng of total RNA was used in a $10 \mu \mathrm{l}$ PCR reaction in a CFX96 Real-Time System Cycler (BioRad, Freiburg, Germany) with SsoAdvanced Universal SYBR Green Supermix (Bio-Rad, München, Germany) with three technical replicates in a CFX96 Real-Time System Cycler (Bio-Rad) in a 40-cycle step amplification protocol $\left(10 \mathrm{~s}\right.$ at $95^{\circ} \mathrm{C} ; 25 \mathrm{~s}$ at $\left.60^{\circ} \mathrm{C}\right)$. The relative quantification was calculated with the $\Delta \Delta \mathrm{Ct}$ method and ACT8 as a control. Relevant primers used are listed in Supplementary Table 3.

NPF3 trafficking analysis. $p 35 S: N P F 3-Y F P$ seedlings were grown for 5 days on MS plates, transferred to $10 \mu \mathrm{M}$ paclo or mock plates for 2 additional days, then treated with $10 \mu \mathrm{M} \mathrm{GA}_{4}$ or mock for $2 \mathrm{~h}$ in liquid media. Before imaging, seedlings were stained with $2 \mu \mathrm{M}$ FM4-64 (mock) or FM4-64 with BFA for $15 \mathrm{~min}$.

Gene synthesis and cloning for transport assays. The genes NPF3, NPF4.1, NPF2.10, NPF2.11 and NPF5.7 were part of a previously published transporter library $^{56}$. Os06g15370 (OsNPF3.1) and Medtr5g055000 (MtNPF3.1) were synthesized by ThermoFisher Scientific Geneart with USER overhangs ${ }^{56,57}$. Coding sequences were cloned into the pNB1 oocyte expression vector ${ }^{58}$ that was made USER cloning compatible ${ }^{56,57}$ and verified by sequencing.

Oocyte preparation and complementary RNA injection. Xenopus oocytes were purchased as defolliculated Xenopus oocytes (stages V-VI) from Ecocyte Biosciences (Germany). Injection of $50 \mathrm{nl}$ complementary RNA (500 $\mathrm{ng}^{-1} \mathrm{l}^{-1}$ ) into Xenopus oocytes was done using a Drummond NANOJECT II (Drummond Scientific). Oocytes were incubated for 3 days at $17^{\circ} \mathrm{C}$ in Kulori $(90 \mathrm{mM} \mathrm{NaCl}$ $1 \mathrm{mM} \mathrm{KCl}, 1 \mathrm{mM} \mathrm{MgCl} 2,10 \mathrm{mM} \mathrm{MES}) \mathrm{pH} 7.5$ before assaying.

Hormone uptake assays. $\mathrm{GA}_{3}$, indole-3-acetic acid, $\mathrm{ABA}$, Gly-Leu, Histidine and $\mathrm{GA}_{4}$ were obtained from Sigma-Aldrich, $\mathrm{GA}_{1}$ was obtained from Toronto Research Chemicals, $\mathrm{GA}_{3}-\mathrm{Fl}$ and $\mathrm{GA}_{4}-\mathrm{Fl}$ were synthesized and characterized as previously described ${ }^{23}$. Briefly, N-Boc-2,2' -(ethylenedioxy) diethylamine was first reacted with 5-(and-6)-carboxyfluorescein succinimidyl ester to form a fluorescein-linker Following deprotection, fluorescein-linker was conjugated to the $\mathrm{C} 6$ carboxylic acid of either $\mathrm{GA}_{3}$ or $\mathrm{GA}_{4}$ to form the corresponding $\mathrm{GA}_{3}-\mathrm{Fl}$ or $\mathrm{GA}_{4}-\mathrm{Fl}$, respectively. $\mathrm{GA}_{12}, \mathrm{GA}_{20}, \mathrm{GA}_{9}, \mathrm{GA}_{8}$ and JA-Ile were obtained from OlChemIm Ltd. (Czech Republic). Xenopus uptake assays were carried out as follows: oocytes were preincubated in Kulori pH5 for $5 \mathrm{~min}$, transferred to Kulori pH 5 with substrate for $60 \mathrm{~min}$ incubation, followed by four washes and transferred to Eppendorf tubes (one oocyte per tube or five oocytes). Excess washing buffer was removed and oocytes were busted in $50 \mu \mathrm{l}$ of $50 \% \mathrm{MeOH}$ and the homogenate was left in the freezer for $2 \mathrm{~h}$. This was followed by centrifugation at $20,000 \mathrm{~g}$ for $15 \mathrm{~min}$ to pellet remaining proteins. The supernatant was transferred to new tubes and diluted with $60 \mu \mathrm{l} \mathrm{H}_{2} \mathrm{O}$. The diluted samples were then filtered through a $0.45 \mu \mathrm{m}$ PVDF-based filter plate (MSHVN4550, Merck Millipore) and subsequently analysed by analytical LC-MS. Extracted data were analysed using Microsoft Excel, statistical analysis and data plotting were done using SigmaPlot version 13.0 (Systat software, USA)

Analysis of hormones and hormone-analogs by LC-MS. Compounds in extracts were directly analysed by LC-MS/MS. Chromatography was performed on an Advance UHPLC system (Bruker, Bremen, Germany). Separation was achieved on a Kinetex $1.7 \mathrm{u}$ XB-C18 column $(100 \times 2.1 \mathrm{~mm}, 1.7 \mu \mathrm{m}, 100 \AA$, Phenomenex, Torrance, CA, USA). Formic acid (0.05\%) in water and acetonitrile (supplied with $0.05 \%$ formic acid) were employed as mobile phases $\mathrm{A}$ and $\mathrm{B}$, respectively. The elution profile was: $0-0.2 \mathrm{~min}, 2 \% \mathrm{~B} ; 0.2-0.9 \mathrm{~min}, 2-30 \% \mathrm{~B} ; 0.9-3.2 \mathrm{~min} 30-100 \%$ B, 3.2-3.7 min $100 \%$; 3.7.-3.8 $\min 100-2 \%$ B and $3.8-5.0 \min 2 \%$ B. The mobile phase flow rate was $400 \mu \mathrm{min}^{-1}$. The column temperature was maintained at $40^{\circ} \mathrm{C}$. The liquid chromatography was coupled to an EVOQ Elite TripleQuad mass spectrometer (Bruker) equipped with an electrospray ion source operated in combined positive and negative ionization mode. The instrument parameters were optimized by infusion experiments with pure standards. The ion spray voltage was maintained at $-4,000 \mathrm{~V}$ for GA and Sinigrin and $+4,000 \mathrm{~V}$ GA-fluorescein analysis, respectively. Cone temperature was set to $300^{\circ} \mathrm{C}$ and cone gas to 20 p.s.i. Heated probe temperature was set to $200^{\circ} \mathrm{C}$ and probe gas flow to 50 p.s.i. Nebulizing gas was set to 60 p.s.i. and collision gas to $1.6 \mathrm{mTorr}$. Nitrogen was used as probe and nebulizing gas and argon as collision gas. Active exhaust was constantly on. Multiple reaction monitoring (MRM) was used to monitor analyte parent ion $\rightarrow$ product ion transitions: MRM transitions were chosen based on direct infusion experiments. Detailed values for mass transitions can be found in Supplementary Table 4. Both Q1 and Q3 quadrupoles were maintained at unit resolution. Bruker MS Workstation software (Version 8.2, Bruker) was used for data acquisition and processing. Linearity in ionization efficiencies were verified by analysing dilution series of standard mixtures. Sinigrin was used as internal standard but not used for quantification. Quantification of all compounds was achieved by external standard curves diluted with the same matrix as the actual samples. Identification of all analytes was achieved by their specific MRM transitions and by chromatographic separation (Supplementary Figs 7, 8 and Supplementary Table 4$)$.

For data presented in Fig. 1b,c and Supplementary Fig. 1a chromatography was performed on an Agilent 1,100 Series LC (Agilent Technologies, Germany). Separation was achieved on a Zorbax SB-C18 column (Agilent; $1.8 \mu \mathrm{m}$, $2.1 \times 50 \mathrm{~mm}$ ) at a flow rate of $0.2 \mathrm{ml} \mathrm{min}^{-1}$. Formic acid $(0.1 \%)$ in water and 
acetonitrile (supplied with $0.1 \%$ formic acid) were employed as mobile phases $\mathrm{A}$ and $\mathrm{B}$, respectively. The elution profile was: $0-0.5 \mathrm{~min}$, isocratic $6 \% \mathrm{~B}$; 0.5-12.5 min, linear gradient 6-55\% B; 12.5-13.1 min, linear gradient $55-95 \%$ B; $13.1-15.5$ isocratic $95 \% \mathrm{~B} ; 15.60-20 \mathrm{~min}$, isocratic $6 \% \mathrm{~B}$. The flow rate was increased to $0.3 \mathrm{ml} \mathrm{min}{ }^{-1}$ in the interval $15.2-17.5 \mathrm{~min}$. The column temperature was maintained at $35^{\circ} \mathrm{C}$. The Bruker HCT-Ultra ion trap mass spectrometer (Bruker Daltonics) was run in positive electrospray mode. Bruker MS Workstation software (Bruker) was used for data acquisition and processing. Linearity in ionization efficiencies were verified by analysing dilution series of standard mixtures. Quantification of all compounds was achieved by external standard curves diluted with the same matrix as the actual samples.

Predicted topology of NPF3. Topologies were defined by the online HMM-top tool (http://www.enzim.hu/hmmtop/) and visualized by the TMRPres2D software (http://biophysics.biol.uoa.gr/TMRPres2D/download.jsp).

Phylogenetic tree of the Arabidopsis NRT/PTR family. Protein sequences for Arabidopsis thaliana NRT/PTR family members were retrieved from TAIR (https://www.arabidopsis.org). Phylogenetic relationship was defined using (http://www.phylogeny.fr//) ${ }^{59-62}$ and visualized with FigTree software (http://tree.bio.ed.ac.uk/software/figtree/).

\section{References}

1. Durbak, A., Yao, H. \& McSteen, P. Hormone signaling in plant development. Curr. Opin. Plant Biol. 15, 92-96 (2012).

2. Wolters, H. \& Jurgens, G. Survival of the flexible: hormonal growth control and adaptation in plant development. Nat. Rev. Genet. 10, 305-317 (2009).

3. Oliva, M., Farcot, E. \& Vernoux, T. Plant hormone signaling during development: insights from computational models. Curr. Opin. Plant Biol. 16, 19-24 (2013).

4. Boursiac, Y. et al. ABA transport and transporters. Trends Plant Sci. 18, 325-333 (2013).

5. Petrasek, J. \& Friml, J. Auxin transport routes in plant development. Development 136, 2675-2688 (2009).

6. Kuromori, T. et al. ABC transporter AtABCG25 is involved in abscisic acid transport and responses. Proc. Natl Acad. Sci. USA 107, 2361-2366 (2010).

7. Kretzschmar, T. et al. A petunia $\mathrm{ABC}$ protein controls strigolactone-dependent symbiotic signalling and branching. Nature 483, 341-344 (2012).

8. Ko, D. et al. Arabidopsis ABCG14 is essential for the root-to-shoot translocation of cytokinin. Proc. Natl Acad. Sci. USA 111, 7150-7155 (2014).

9. Zhang, K. et al. Arabidopsis ABCG14 protein controls the acropetal translocation of root-synthesized cytokinins. Nat. Commun. 5, 3274 (2014).

10. Blilou, I. et al. The PIN auxin efflux facilitator network controls growth and patterning in Arabidopsis roots. Nature 433, 39-44 (2005).

11. Vanneste, S. \& Friml, J. Auxin: a trigger for change in plant development. Cell 136, 1005-1016 (2009).

12. Kanno, Y. et al. Identification of an abscisic acid transporter by functional screening using the receptor complex as a sensor. Proc. Natl Acad. Sci. USA 109, 9653-9658 (2012).

13. Hedden, P. The genes of the Green Revolution. Trends Genet. 19, 5-9 (2003).

14. Ragni, L. et al. Mobile gibberellin directly stimulates Arabidopsis hypocotyl xylem expansion. Plant Cell 23, 1322-1336 (2011).

15. Eriksson, S., Bohlenius, H., Moritz, T. \& Nilsson, O. $\mathrm{GA}_{4}$ is the active gibberellin in the regulation of LEAFY transcription and Arabidopsis floral initiation. Plant Cell 18, 2172-2181 (2006).

16. Dayan, J. et al. Leaf-induced gibberellin signaling is essential for internode elongation, cambial activity, and fiber differentiation in tobacco stems. Plant Cell 24, 66-79 (2012).

17. Phillips, I. \& Hartung, W. Longitudinal and lateral transport of [3, 4-3H-] gibberelling A1 and 3-Indoly (acetic acid-2-14C) in upright and geo-tropically responding green internode segments from helanthus annuus. New Phytol. 76, 1-9 (1976).

18. Altman, A. \& Mozes, R. Comparative basipetal transport of 6benzylaminopurine-8-14C, gibberellin A3-3H, IAA-2-14C, and sucrose-14C in the root of intact citrus aurantium seedlings. Physiol. Plant. 39, 233-235 (1977).

19. Nash, L. J. \& Crozier, A. Translocation and metabolism of [3H] gibberellins by light-grown Phaseolus coccineus seedlings. Planta 127, 221-231 (1975).

20. Regnault, T. et al. The gibberellin precursor GA12 acts as a long-distance growth signal in Arabidopsis. Nat. Plants 1, 15073 (2015).

21. Mander, L. N. The chemistry of gibberellins: an overview. Chem. Rev. 92, 573-612 (1992).

22. Kramer, E. M. How far can a molecule of weak acid travel in the apoplast or xylem? Plant Physiol. 141, 1233-1236 (2006).

23. Shani, E. et al. Gibberellins accumulate in the elongating endodermal cells of Arabidopsis root. Proc. Natl Acad. Sci. USA 110, 4834-4839 (2013).

24. Band, L. R. \& Bennett, M. J. Mapping the site of action of the Green Revolution hormone gibberellin. Proc. Natl Acad. Sci. USA 110, 4443-4444 (2013).
25. Garcia, O., Bouige, P., Forestier, C. \& Dassa, E. Inventory and comparative analysis of rice and Arabidopsis ATP-binding cassette (ABC) systems. J. Mol. Biol. 343, 249-265 (2004).

26. Leran, S. et al. A unified nomenclature of NITRATE TRANSPORTER 1/PEPTIDE TRANSPORTER family members in plants. Trends Plant Sci. 19, 5-9 (2014).

27. Kang, J. et al. PDR-type ABC transporter mediates cellular uptake of the phytohormone abscisic acid. Proc. Natl Acad. Sci. USA 107, 2355-2360 (2010).

28. Mravec, J. et al. Interaction of PIN and PGP transport mechanisms in auxin distribution-dependent development. Development 135, 3345-3354 (2008).

29. Geisler, M. \& Murphy, A. S. The ABC of auxin transport: the role of p-glycoproteins in plant development. FEBS Lett. 580, 1094-1102 (2006).

30. Krouk, G. et al. Nitrate-regulated auxin transport by NRT1. 1 defines a mechanism for nutrient sensing in plants. Dev. Cell 18, 927-937 (2010).

31. Pike, S. et al. Members of the NPF3 transporter subfamily encode pathogeninducible nitrate/nitrite transporters in grapevine and Arabidopsis. Plant Cell Physiol. 55, 162-170 (2014).

32. Sugiura, M., Georgescu, M. N. \& Takahashi, M. A nitrite transporter associated with nitrite uptake by higher plant chloroplasts. Plant Cell Physiol. 48, 1022-1035 (2007).

33. Chiba, Y. et al. Identification of Arabidopsis thaliana NRT1/PTR family (NPF) proteins capable of transporting plant hormones. J. Plant Res. 128, 679-686 (2015).

34. Saito, H. et al. The jasmonate-responsive GTR1 transporter is required for gibberellin-mediated stamen development in Arabidopsis. Nat. Commun. 6, 6095 (2015).

35. Petrasek, J. et al. PIN proteins perform a rate-limiting function in cellular auxin efflux. Science 312, 914-918 (2006).

36. Friml, J. et al. Efflux-dependent auxin gradients establish the apical-basal axis of Arabidopsis. Nature 426, 147-153 (2003).

37. Barbez, E. et al. A novel putative auxin carrier family regulates intracellular auxin homeostasis in plants. Nature 485, 119-122 (2012).

38. Mravec, J. et al. Subcellular homeostasis of phytohormone auxin is mediated by the ER-localized PIN5 transporter. Nature 459, 1136-1140 (2009).

39. Ranocha, P. et al. Arabidopsis WAT1 is a vacuolar auxin transport facilitator required for auxin homoeostasis. Nat. Commun. 4, 2625 (2013).

40. Brady, S. M. et al. A high-resolution root spatiotemporal map reveals dominant expression patterns. Science 318, 801-806 (2007).

41. Mustroph, A. et al. Profiling translatomes of discrete cell populations resolves altered cellular priorities during hypoxia in Arabidopsis. Proc. Natl Acad. Sci. USA 106, 18843-18848 (2009).

42. Vieten, A. et al. Functional redundancy of PIN proteins is accompanied by auxin-dependent cross-regulation of PIN expression. Development 132, 4521-4531 (2005).

43. Goda, H. et al. The AtGenExpress hormone and chemical treatment data set: experimental design, data evaluation, model data analysis and data access. Plant J. 55, 526-542 (2008).

44. Böhmer, M. \& Schroeder, J. I. Quantitative transcriptomic analysis of abscisic acid-induced and reactive oxygen species-dependent expression changes and proteomic profiling in Arabidopsis suspension cells. Plant J. 67, 105-118 (2011).

45. Kilian, J. et al. The AtGenExpress global stress expression data set: protocols, evaluation and model data analysis of UV-B light, drought and cold stress responses. Plant J. 50, 347-363 (2007).

46. Sun, T., Goodman, H. M. \& Ausubel, F. M. Cloning the Arabidopsis GA1 locus by genomic subtraction. Plant Cell 4, 119-128 (1992).

47. Regnault, T., Davière, J. M., Heintz, D., Lange, T. \& Achard, P. The gibberellin biosynthetic genes AtKAO1 and AtKAO2 have overlapping roles throughout Arabidopsis development. Plant J. 80, 462-474 (2014).

48. Jorgensen, M. E. et al. A functional EXXEK motif is essential for proton coupling and active glucosinolate transport by NPF2.11. Plant Cell Physiol. 56, 2340-2350 (2015).

49. Nour-Eldin, H. H. et al. NRT/PTR transporters are essential for translocation of glucosinolate defence compounds to seeds. Nature 488, 531-534 (2012).

50. Tsay, Y. F., Schroeder, J. I., Feldmann, K. A. \& Crawford, N. M. The herbicide sensitivity gene CHL1 of Arabidopsis encodes a nitrate-inducible nitrate transporter. Cell 72, 705-713 (1993).

51. Chiang, C. S., Stacey, G. \& Tsay, Y. F. Mechanisms and functional properties of two peptide transporters, AtPTR2 and fPTR2. J. Biol. Chem. 279, 30150-30157 (2004).

52. Frommer, W. B., Hummel, S. \& Rentsch, D. Cloning of an Arabidopsis histidine transporting protein related to nitrate and peptide transporters. FEBS Lett. 347, 185-189 (1994).

53. Proebsting, W. M., Hedden, P., Lewis, M. J., Croker, S. J. \& Proebsting, L. N. Gibberellin concentration and transport in genetic lines of pea: effects of grafting. Plant Physiol. 100, 1354-1360 (1992). 
54. Ubeda-Tomas, S. et al. Root growth in Arabidopsis requires gibberellin/DELLA signalling in the endodermis. Nat. Cell Biol. 10, 625-628 (2008).

55. Ubeda-Tomas, S. et al. Gibberellin signaling in the endodermis controls Arabidopsis root meristem size. Curr. Biol. 19, 1194-1199 (2009).

56. Nour-Eldin, H. H., Nørholm, M. H. \& Halkier, B. A. Screening for plant transporter function by expressing a normalized Arabidopsis full-length cDNA library in Xenopus oocytes. Plant Methods 2, 1 (2006).

57. Geu-Flores, F., Nour-Eldin, H. H., Nielsen, M. T. \& Halkier, B. A. USER fusion: a rapid and efficient method for simultaneous fusion and cloning of multiple PCR products. Nucleic Acids Res. 35, e55 (2007).

58. MacAulay, N., Gether, U., Klærke, D. A. \& Zeuthen, T. Water transport by the human $\mathrm{Na}+$-coupled glutamate cotransporter expressed in Xenopus oocytes. J. Physiol. 530, 367-378 (2001).

59. Dereeper, A., Audic, S., Claverie, J.-M. \& Blanc, G. BLAST-EXPLORER helps you building datasets for phylogenetic analysis. BMC Evol. Biol. 10, 8 (2010).

60. Dereeper, A. et al. Phylogeny. fr: robust phylogenetic analysis for the nonspecialist. Nucleic Acids Res. 36, W465-W469 (2008).

61. Guindon, S. \& Gascuel, O. A simple, fast, and accurate algorithm to estimate large phylogenies by maximum likelihood. System. Biol. 52, 696-704 (2003).

62. Anisimova, M. \& Gascuel, O. Approximate likelihood-ratio test for branches: a fast, accurate, and powerful alternative. System. Biol. 55, 539-552 (2006).

\section{Acknowledgements}

This work was supported by grants from the Israel Science Foundation (1832/14) and (2158/14; E.S.), the German Israeli Foundation for Scientific Research and Development (I-236-203.17-2014; C.S. and E.S.), Nirit and Michael Shaoul Fund for Visiting Scholars and Fellows (C.S. and E.S.), the Human Frontier Science Program (HFSP-RGY0075/ 2015; E.S. and H.H.N.-E.), the National Institutes of Health (GM43644; M.E.), the Howard Hughes Medical Institute (M.E.), the Gordon and Betty Moore Foundation (M.E.) and the Danish National Research Foundation (DNRF99).

\section{Author contributions}

I.T., E.S. and M.E. conceived and designed the study and wrote the manuscript. I.T. performed the genetic, physiological and imaging work. Y.Z. carried out the genetic screens and genotyped the mutants. M.E.J. performed the oocyte transport assays C.C. and C.E.O. performed the LC-MS measurements. O.P. assisted with the cloning and antibodies. I.C.R.B. performed subcellular trafficking experiments. T.R. performed gene expression analyses. R.W. synthesized the fluorescent GA molecules and provided scientific guidance throughout the project. B.A.H., H.H.N.-E. and C.S. designed experimental protocols and edited the manuscript. All authors discussed the results and commented on the manuscript.

\section{Additional information}

Supplementary Information accompanies this paper at http://www.nature.com/ naturecommunications

Competing financial interests: The authors declare no competing financial interests.

Reprints and permission information is available online at http://npg.nature.com/ reprintsandpermissions/

How to cite this article: Tal, I. et al. The Arabidopsis NPF3 protein is a GA transporter. Nat. Commun. 7:11486 doi: 10.1038/ncomms11486 (2016)

(c) (i) This work is licensed under a Creative Commons Attribution 4.0 International License. The images or other third party material in this article are included in the article's Creative Commons license, unless indicated otherwise in the credit line; if the material is not included under the Creative Commons license, users will need to obtain permission from the license holder to reproduce the material. To view a copy of this license, visit http://creativecommons.org/licenses/by/4.0/ 